\title{
Influence of water shortage on apple seedling growth under different radiation composition
}

\author{
F.A. HAMANN ${ }^{1, *}$, A. FIEBIG ${ }^{1}$, and G. NOGA ${ }^{1}$ \\ ${ }^{1}$ University of Bonn, Institute of Crop Science and Resource Conservation, Horticultural Sciences, D-53121-Bonn, \\ Germany
}

${ }^{*}$ Corresponding author: E-mail: hamann_ufsm@hotmail.com

\begin{abstract}
Abiotic stresses strongly impair plant development and might impose detrimental effects particularly on seedlings. Irradiance and water deficit are relevant factors, which affect performance of young plants under controlled conditions. In our study, we investigated the influence of water shortage combined with different radiation sources - light emitting diodes (LED) and compact fluorescence lamps (CFL) - on physiological and biochemical parameters of young apple plants. Stress responses were assessed by fluorescence-based indices, while relative water, chlorophyll (Chl), and proline content served as reference parameters. The watering regime had a higher impact on biochemical indicators than the radiation sources. Lower Chl content was determined in plants grown under LED both in control and in water deficit plants. Nitrogen balance index and nitrogen balance index with red radiation excitation showed similar patterns regarding leaf $\mathrm{Chl}$ results in relation to the radiation source, being higher under CFL. In contrast, the flavonol index was higher in plants cultivated under LED. Stomatal conductance and maximal photochemical efficiency emphasised a radiation quality effect with higher values for CFL. In conclusion, fluorescence indices related to nitrogen status and flavonol content are promising parameters to sense physiological impairments under the given conditions. However, discrepancies compared to previous studies might be related to the different plant species, the nature of dehydration, and the measuring conditions.
\end{abstract}

Keywords: compact fluorescence lamps, light emitting diodes, portable fluorescence sensors, water deficit.

\section{Introduction}

Improper radiation sources and limitation of water supply can significantly impair the development of seedlings, where is a high susceptibility of lipids, proteins, and nucleic acids to damage, resulting in various biochemical and physiological disorders, and consequently in yield loses (Osakabe et al. 2014, Nouri et al. 2015).

In controlled (climate-chamber) and semi-controlled (greenhouse) conditions, a broad range of artificial radiation, e.g., sodium vapour lamps, compact fluorescence lamps (CFL), and light emitting diodes (LED), are commonly used to reach optimal photosynthetic active radiation. Most LED systems provide mainly red and blue radiation, which in comparison to green radiation is the most absorbed part of spectrum by photosynthetic pigments and provides most energy for photosynthesis (Kim et al. 2005, Massa et al. 2008, Astolfi et al. 2012). Nevertheless, under strong white radiation, green radiation might drive leaf photosynthesis even more efficiently than red radiation (Terashima et al. 2009). Excessive blue radiation might initiate a chloroplast avoidance response

$\overline{\text { Received }} 21$ July 2019, last revision 31 May 2020, accepted 4 June 2020.

Abbreviations: CFL - compact fluorescence lamps; CFL WD - compact fluorescence lamps and water deficit; Chl - chlorophyll; Chl INDEX - chlorophyll index; DAS - days after sowing; Flav Dx - flavonol index (Dualex ${ }^{\mathbb{R}}$ ); Flav Mx - flavonol index (Multiplex $\left.{ }^{\mathbb{R}}\right)$; $\mathrm{F}_{\mathrm{v}} / \mathrm{F}_{\mathrm{m}}$ - variable to maximum Chl fluorescence (maximum quantum efficiency of PS II); $\mathrm{g}_{\mathrm{s}}$ - stomatal conductance; LED - light emitting diodes; LED_WD - led emitting diodes and water deficit; NBI - nitrogen balance index; NBI R - nitrogen balance index with red excitation; PĀM - pulse amplitude modulation; PPFD - photosynthetic photon flux density; PS - photosystem; RWC - leaf relative water content; SFR R - simple fluorescence ratio with red excitation.

Acknowledgements: This study was financially supported by the National Council for Scientific and Technological Development (CNPq) and Ministry of Science and Technology of the Federal Government of Brazil, and conducted at the Department of Horticultural Science of the University of Bonn.

Conflict of interest: The authors declare that they have no conflict of interest. 
as well as a decrease in mesophyll conductance resulting in decreased photosynthetic efficiency (Loreto et al. 2009). In summary, these studies suggest that a fine balance in choosing the right radiation spectrum for plant cultivation is essential.

Radiation quality might also support plants in protecting them against water shortage by mediating stomatal aperture and controlling transpiration (Zeiger and Field 1982, Chen et al. 2012). On these terms, Hoffmann et al. (2015) demonstrated that blue radiation caused structural and functional acclimations at pepper plants at leaf and cellular levels. In the same study, morphological acclimations contributed to different water requirements, while photosynthetic acclimations, affected by the composition of chloroplasts, reduced susceptibility to a short-term water deficit (Hoffmann et al. 2015). Generally, wide-spread information on the interaction between radiation quality and physiological responses of plants to water deficit is still missing. A more precise knowledge of such interactions could contribute to promote a new outlook for purposeful applications of radiation quality to reduce negative impacts of stress conditions on ornamental and horticultural plants.

Methods to assess plant responses to the effect of radiation and water supply mostly depend on destructive and time-consuming determination of biochemical indicators, such as chlorophyll (Chl), nitrogen, and proline content, and physiological indicators, such as water and osmotic potentials, as well as relative water content (RWC). However, non-destructive sensing methods have also been applied in plant breeding systems to minimise these limitations on evaluating stress responses. Among others, the use of fluorescence approaches with pulse-amplitudemodulation (PAM) has gained attention (Roháček et al. 2008, Lichtenthaler et al. 2013).

Fluorescence of Chl molecules, emitted in the red (R) and far-red (FR) spectral regions, is the basis of a widely applied technique with the purpose to evaluate impacts of adverse environmental conditions on plant physiology (Bürling et al. 2013, Lichtenthaler et al. 2013, Kautz et al. 2014). Chlorophyll $a$ and $b$ emits fractions of absorbed radiation energy as fluorescence (Buschmann and Lichtenthaler 1999). Besides traditional methods based on the PAM method, Chl fluorescence can also be detected through multi-indices fluorescence excitation approaches (Tremblay et al. 2012). Variations in the fluorescence signature caused by alterations in the amount and composition of fluorescing pigments besides $\mathrm{Chl}$ can be used as additional indicators to broaden the assessment of the environmental impact on plant physiology (Gitelson et al. 1999). Portable fluorescence sensors have been developed to facilitate the assessment of secondary metabolites, such as phenolic compounds in the leaf epidermis. Their synthesis is frequently triggered as a protective mechanism against environmental stresses as imbalance reaction to the primary metabolism. Different ratios and indices can be calculated depending on the incident radiation excitation and collected fluorescence signals to estimate a plant physiological status by means of Chl, flavonol, and nitrogen content (Ghozlen et al. 2010,
Cerovic et al. 2012, Tremblay et al. 2012).

In addition, studies with different species are important to understand how, for example, the morphological structure will influence fluorescence measurements. Species, such as sweet peppers, with a shorter growing phase, low lignified stems, and thicker leaf layer, might have a different fluorescence signature than species with a longer growing phase, more lignified stem, and thinner leaves, such as Malus domestica (Kautz et al. 2015, Hamann et al. 2018). Our study hypothesises that specific radiation-mediated acclimations at plant and leaf levels reduce the vulnerability of apple seedlings to water deficit. In particular, the aim of this study was to investigate the physiological responses of apple seedlings cultivated either under CFL or under LEDs and additionally subjected to a period of water shortage.

\section{Materials and methods}

Plants, growth conditions, and experimental setup: The trial was conducted in a custom-built climate chamber. Seeds of Malus domestica Borkh. cv. Golden Delicious were stratified at $4{ }^{\circ} \mathrm{C}$ in the dark for $28 \mathrm{~d}$. Subsequently, they were sown in sterilized trays filled with a mixture of peat $(60 \%)$, sand $(20 \%)$, and Perlite $(20 \%)$ and allocated under white compact fluorescence lamps (CFL) with main radiation peaks at 435, 545, and $612 \mathrm{~nm}$ (MASTER PL-L 4P, Cool Daylight, $30{ }^{\circ} \mathrm{C}$, Philips, Amsterdam, The Netherlands) (Hoffmann et al. 2015). The photosynthetic photon flux density (PPFD) of CFL was set to $95 \mu \mathrm{mol} \mathrm{m}{ }^{-2} \mathrm{~s}^{1}$ whereby $14 \%$ of the radiation energy was provided by blue, $40 \%$ by green, and $46 \%$ by red radiation.

Five weeks after sowing, seedlings were transplanted into pots $(11 \mathrm{~cm}$, Lamprecht-Verpackungen, Göttingen, Germany) filled with $250 \mathrm{~g}$ of the above described peatsand-Perlite mixture and cultivated under the same environmental conditions for three additional weeks. Next, half of the plants were kept under CFL while the remaining plants were allocated under LED modules (a prototype optimised for our research purposes; Ushio Lighting, Tokyo, Japan). The LED-modules were characterized by a 2:1 combination of red and blue LEDs with single peaks at 665 and $445 \mathrm{~nm}$, respectively. The PPFD of the LED modules was also set to $95 \pm 5 \mu \mathrm{mol} \mathrm{m}^{-2} \mathrm{~s}^{-1}$, whereby $36 \%$ of the energy was provided by blue radiation and $64 \%$ by red radiation. Plants were cultivated under a 12 -h photoperiod, day/night temperatures of $21 / 20^{\circ} \mathrm{C}$, and relative humidity of $80 \%$. One week after the plants were assigned to the respective radiation source (CFL or LED), the water supply treatments were initiated (63 d after sowing; DAS). After the substrate was saturated with a Hoagland nutrient solution ( $\mathrm{pH} 6.2$, electrical conductivity $1.4 \mathrm{mS} \mathrm{cm}^{-1}$ ), drought stress was induced by withholding water and nutrient solution for $15 \mathrm{~d}$ (63 - 78 DAS), followed by a recovery period for $8 \mathrm{~d}$ (78 - 86 DAS). Control plants were irrigated daily according to their needs throughout the experiment. The experimental treatments were identified as follows: CFL - compact fluorescence lamps (control), CFL_WD - CFL + water deficit, LED - 
light-emitting diodes (control), LED WD - LED + water deficit. The experiment was separated into three different watering phases: well-watered - when all plants were completely watered to soil saturation, water deficit - when watering of the plants was withheld, and recovery - when all plants were re-watered to pot saturation.

Physiological and biochemical indicators: The so-called reference parameters were assessed in a destructive way to compare with, and validate against, the parameters assessed by fluorescence devices. Leaves were harvested and sampled on 71, 76, and 83 DAS to evaluate leaf relative water content, $\mathrm{Chl}$ content, and proline content.

Relative water content (RWC), as a measure of leaf hydration status (Mullan and Pietragalla 2012), was measured according to the method described by Barrs and Weatherley (1962) with few adaptations. Disc of $2.10 \mathrm{~cm}^{2}$ was excised from leaves with a sharp cork borer to avoid leaf veins. Discs were then weighed to obtain leaf fresh mass (FM), after which the samples were hydrated in Petri dishes overnight to obtain fully saturated mass (FSM). Samples were then oven dried at $80{ }^{\circ} \mathrm{C}$ overnight to determine dry mass (DM). The RWC was calculated as described by González and González-Vilar (2001).

Chlorophyll content was assessed by applying the method described by Strobl and Türk (1990). Three fully expanded leaves of each seedling on each measurement day were collected and cold-transported to the lab, immediately frozen $\left(-20^{\circ} \mathrm{C} \pm 2\right)$, freeze-dried, ground for 1 min using a ball mill (MM 2000, Retsch, Haan, Germany) and $5 \mathrm{~cm}^{3}$ of methanol were added to $50 \mathrm{mg}$ of the dried and ground sample, mixed, and centrifuged at $4000 \mathrm{rpm}$ for $15 \mathrm{~min}$ (Varifuge 3 OR, Heraeus Sepatech, Hanau, Germany). Absorbance of the extracts was quantified by a UV-VIS spectrophotometer (Lambda 35, Perkin-Elmer, Waltham, MA, USA) at 650 and $665 \mathrm{~nm}$. Chlorophyll content was calculated using formulas given in Hoffmann et al. (2015).

Proline content was determined colourimetrically according to the method described by Abrahám et al. (2010) with slight modifications. Briefly, $3 \mathrm{~cm}^{3}$ of sulfosalicylic acid $(3 \%, \mathrm{~m} / \mathrm{v})$ were added to $0.1 \mathrm{~g}$ of dried and ground leaf material, and the mixture was homogenized and centrifuged at $4000 \mathrm{rpm}$ for $15 \mathrm{~min}$ (Varifuge 3.0R). Next, $0.2 \mathrm{~cm}^{3}$ of the supernatant was added to $1.8 \mathrm{~cm}^{3}$ of sulfosalicylic acid, $2 \mathrm{~cm}^{3}$ of glacial acetic acid, and $2 \mathrm{~cm}^{3}$ of ninhydrine acid and incubated in a hot water bath $\left(100^{\circ} \mathrm{C}\right)$ for $1 \mathrm{~h}$. After cooling to $20^{\circ} \mathrm{C}$, $4 \mathrm{~cm}^{3}$ of toluene was added and mixed. The absorbance of the supernatant was measured at $520 \mathrm{~nm}$ with a UVspectrophotometer (Lambda 35). Proline content was calculated from a standard curve.

Fluorescence measurements: Fluorescence indices were assessed by two portable fluorescence sensors, Dualex ${ }^{\circledR} 4$ Scientific and Multiplex $₫ 3$ (Force-A, Orsay, France). They were adopted to record conditions during the experiment. These devices can be used for instant evaluation of the plant status both under natural irradiance in the field or under artificial irradiance in controlled chambers. Three different leaves per plant distributed in the lower, middle, and upper part of the seedling were selected and recordings were taken on $63,66,69,71,73,76,78,83$, and 86 DAS.

The hand-held sensor Dualex $\AA_{4}$ Scientific combines the use of fluorescence and radiation transmission of a leaf (Cerovic et al. 2012). It determines the absorbance of the leaf epidermis in the ultraviolet (UV) range through the differential measurement of the Chl fluorescence and can also estimate the $\mathrm{Chl}$ content of the leaf using different wavelengths in red (R) and in far-red (FR) regions. In this study, Chl index (Chl INDEX), flavonol index (Flav Dx), and nitrogen balance index (NBI) were measured. The calculation details of these parameters can be found in the literature (Cerovic et al. 2012, Tremblay et al. 2012, and briefly mentioned in Table 1 Suppl.).

The portable multi-parametric fluorescence sensor Multiplex ${ }^{\circledR} 3$ uses LED which excite the plant material at three excitation channels in spectral regions of $375 \mathrm{~nm}$ (UV), $518 \mathrm{~nm}$ (green), and $630 \mathrm{~nm}$ (red). The plant fluorescence was detected in red (RF 680 - $690 \mathrm{~nm}$ ) and far-red (FRF 720 - $755 \mathrm{~nm}$ ) spectral regions. A disc with an aperture of $4 \mathrm{~cm}$ was used in front of the optical unit to enable the measurement of an area of approximately $12.5 \mathrm{~cm}^{2}$ by maintaining a constant distance of $10 \mathrm{~cm}$ between the radiation source in the device and the measured leaf surface. The analysed indices obtained by Multiplex ${ }^{\circledR} 3$ were SFR R, NBI R, and Flav Mx. The description of these parameters and their calculations can be found in Bürling et al. (2011), Zhang et al. (2012), Leufen et al. (2014), Hoffmann et al. (2015), and in Table 1 Suppl.

Maximum quantum efficiency of PS (photosystem) II $\left(\mathrm{F}_{\mathrm{v}} / \mathrm{F}_{\mathrm{m}}\right)$ was recorded once a week using an imaging pulseamplitude-modulated fluorometer (Imaging PAM, HeinzWalz, Effeltrich, Germany). Fluorescence images (640 × 480 pixels) were taken by a black and white CCD camera on fully expanded leaves at the third leaf insertion level. To standardize measuring conditions and to make sure that all PS II reaction centres were open when the maximal photochemical quenching was determined, plants were dark-adapted for $30 \mathrm{~min}$ prior to the evaluations (see the review of Maxwell and Johnson 2000). After recording the ground fluorescence $\left(\mathrm{F}_{0}\right)$, a radiation saturation pulse was given to determine the maximum fluorescence yield $\left(\mathrm{F}_{\mathrm{m}}\right)$. Measurements were performed on 63, 71, 76, and 83 DAS.

Correlation between maximum quantum efficiency of PS II $\left(\mathrm{F}_{\mathrm{v}} / \mathrm{F}_{\mathrm{m}}\right)$ and Chl fluorescence indices, represented by the fluorescence indices (Chl INDEX and SFR R), were portrayed in diagrams with linear regression and coefficient of determination $\left(R^{2}\right)$.

Stomatal conductance $\left(\mathrm{g}_{\mathrm{s}}\right)$ was recorded with a portable infrared gas analyser (CIRAS-1, PP Systems, Amesbury, USA) equipped with a standard $2.5 \mathrm{~cm}^{2}$ leaf cuvette (PLC B, PP Systems). Measurements were carried out under the corresponding CFL and LED irradiance with adopted standardised settings: $\mathrm{CO}_{2}$ concentration $350 \pm$ $5 \mu \mathrm{mol} \mathrm{mol}{ }^{-1}$, PPFD of $100 \pm 5 \mu \mathrm{mol} \mathrm{m} \mathrm{m}^{-2}$, a boundary layer resistance $(\mathrm{Rb})$ of $0.27 \mathrm{~m}^{2} \mathrm{~s} \mathrm{~mol}^{-1}$, and a leaf chamber air flow rate of $200 \mathrm{~cm}^{3} \mathrm{~min}^{-1}$. 
Statistics: Statistical procedure was performed with the SPSS statistic software (PASW statistics version 25.0, $S P S S$, Chicago, USA). For this, a two-way ANOVA $(P \alpha=0.05)$, determining the impact of radiation quality and water supply as well as the interaction between both, was performed. A linear relation with the coefficient of determination $\left(R^{2}\right)$ between Chl-based fluorescence indices, maximum photochemical efficiency of PS II, and the leaf Chl content was also performed.

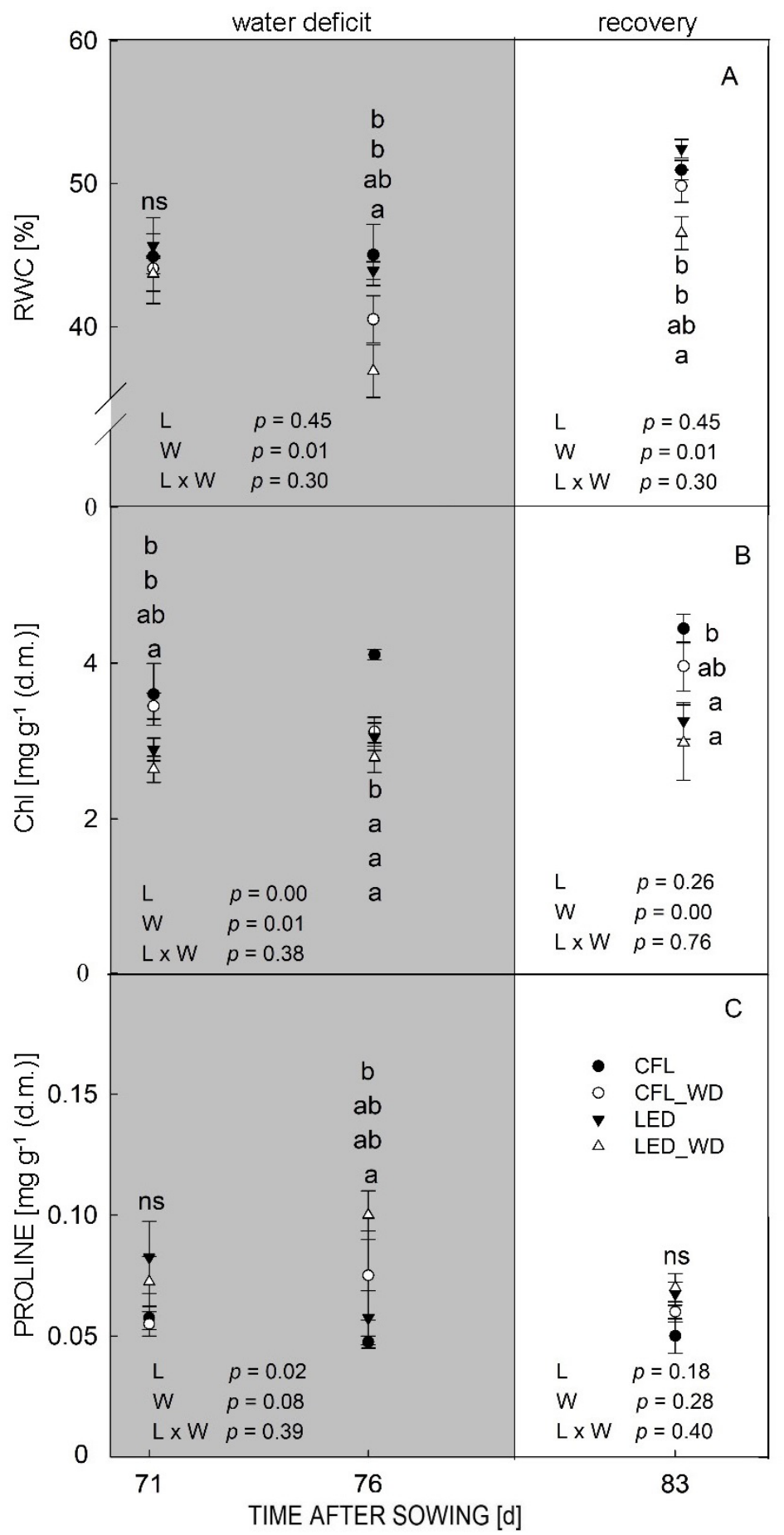

Fig. 1. $A$ - leaf relative water content (RWC), $B$ - leaf chlorophyll content (Chl), and $C$ - leaf proline content of apple seedlings cultivated in a climate chamber under different radiation sources (CFL - compact fluorescence lamps and LED - light emitting diodes) during progressive water stress $(71$ and 76$)$ and recovery $(83 \mathrm{~d})$. Treatments: CFL - control plants grown under CFL, CFL WD - water deficit plants grown under CFL, LED - control plants grown under LED, and LED_WD water deficit plants grown under LED. Means \pm SEs, $n=15$, different letters indicate significant differences between treatments (two-way ANOVA, L - irradiance, $\mathrm{W}-\mathrm{watering}, \mathrm{L} \times \mathrm{W}$ - interaction). 


\section{Results}

Mean values of RWC showed no significant differences during the early water deficit phase (71 DAS). A higher RWC was seen in well-watered plants on 76 DAS compared to the water deficit treatments. During the recovery phase (83 DAS), water restricted plants subjected to LED treatment (LED_WD) presented lower RWC mean values than other treatments (Fig. $1 A$ ).

Radiation quality and watering regimes significantly affected total leaf Chl content during water deficit and recovery phases. Lowest leaf $\mathrm{Chl}$ content was measured in LED_WD plants, followed by their well-watered control plants. In contrast, the highest values were seen in CFL well-watered plants during the course of the experiment; Chl content only slightly decreased on 76 DAS for CFL_ WD plants (Fig. 1B).
The lowest proline content was recorded for CFL plants throughout the experimental period (Fig. 1C). Even though there were no significant differences, LED and LED WD showed a higher proline content on 71 DAS. On $7 \overline{6}$ DAS, higher proline content was seen in both water deficit treatments. These differences faded at 83 DAS (recovery period).

Chlorophyll estimation by Chl INDEX and SFR R show increasing values throughout the treatment period. In addition, the lowest Chl INDEX values were recorded in CFL well-watered plants during the whole course of the experiment (Fig. 2A). In contrast, significantly higher Chl INDEX was recorded for LED WD plants on 76 DAS and for LED well-watered plants on 78 DAS as well as on 83 and 86 DAS.

Interestingly, the SFR $\mathrm{R}$ index showed more pronounced differences between the treatments. Already at

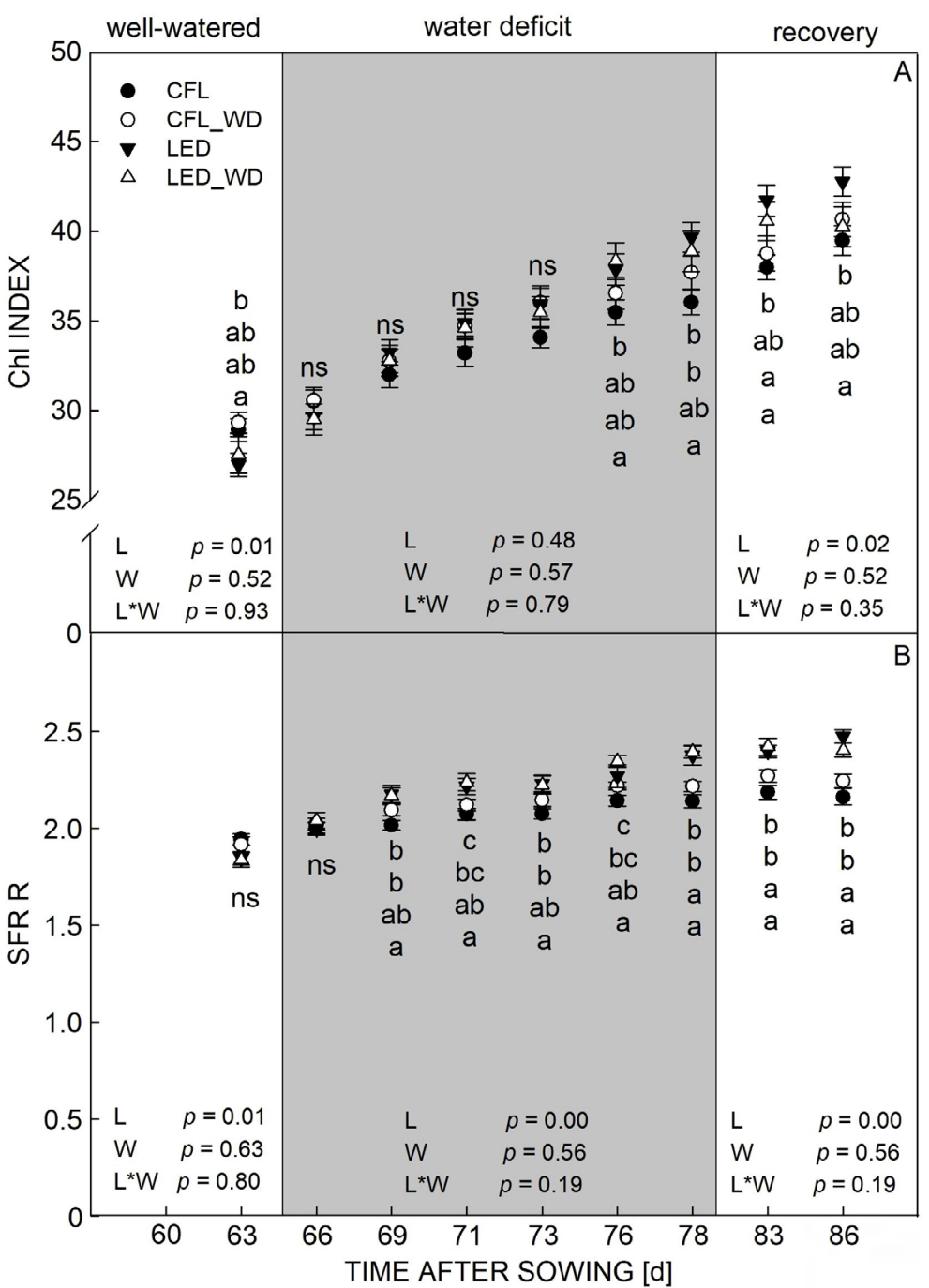

Fig. 2. Chlorophyll fluorescence indices Chl Index $(A)$ and SFR R $(B)$ assessed by Dualex ${ }^{\circledR}$ and Multiplex ${ }^{\circledR}$, respectively, in apple seedlings cultivated in a climate chamber under different radiation sources (CFL - compact fluorescence lamps and LED - light emitting diodes) during well-watered phase $(63 \mathrm{~d})$, progressive water stress $66-78 \mathrm{~d})$ and recovery $(83$ and $86 \mathrm{~d})$. Treatments: CFL - control plants grown under CFL, CFL_WD - water deficit plants grown under CFL, LED - control plants grown under LED, and LED_WD water deficit plants grown under LED. Means \pm SEs, $n=60$, different letters indicate significant differences between treatments (twoway $A N O V A, \mathrm{~L}$ - irradiance, $\mathrm{W}$ - watering, $\mathrm{L} \times \mathrm{W}$ - interaction). 
69 DAS, significantly higher values were recorded in both water deficit treatments (CFL WD and LED WD) when compared to the well-watered plants (Fig. 2B). On 76 DAS, increased values were seen in both LED treatments and this trend continued throughout the recovery phase. Significantly lower values were recorded for CFL plants on 78,83 , and 86 DAS.

Nitrogen balance status was assessed by two indices, NBI and NBI R, as a factor of the Chl content in mesophyll and the content of phenolic compounds in leaf epidermis (Fig. 3). Irrespectively of the watering regime, higher values for both indices were recorded for plants grown under CFL than under LED. For NBI, this effect was seen from 66 DAS onwards (Fig. $3 A$ ), whereas NBI R recorded significant differences already on 63 DAS (Fig. $3 B$ ). The NBI was not able to identify significant differences between the control and water deficient plants (Fig. 3A). In contrast, the NBI R showed highest values for CFL WD plants (significant on 78 DAS). On this day, LED WD plants also showed significantly higher values when compared with respective well-watered plants. This effect faded during the recovery phase.

In Fig. 4, the fluorescence indices estimating the epidermal flavonols are displayed. In contrast to the NBI indices, significantly highest values (both Flav Dx, Fig. $4 A$ and Flav Mx, Fig. 4B) were recorded for plants grown

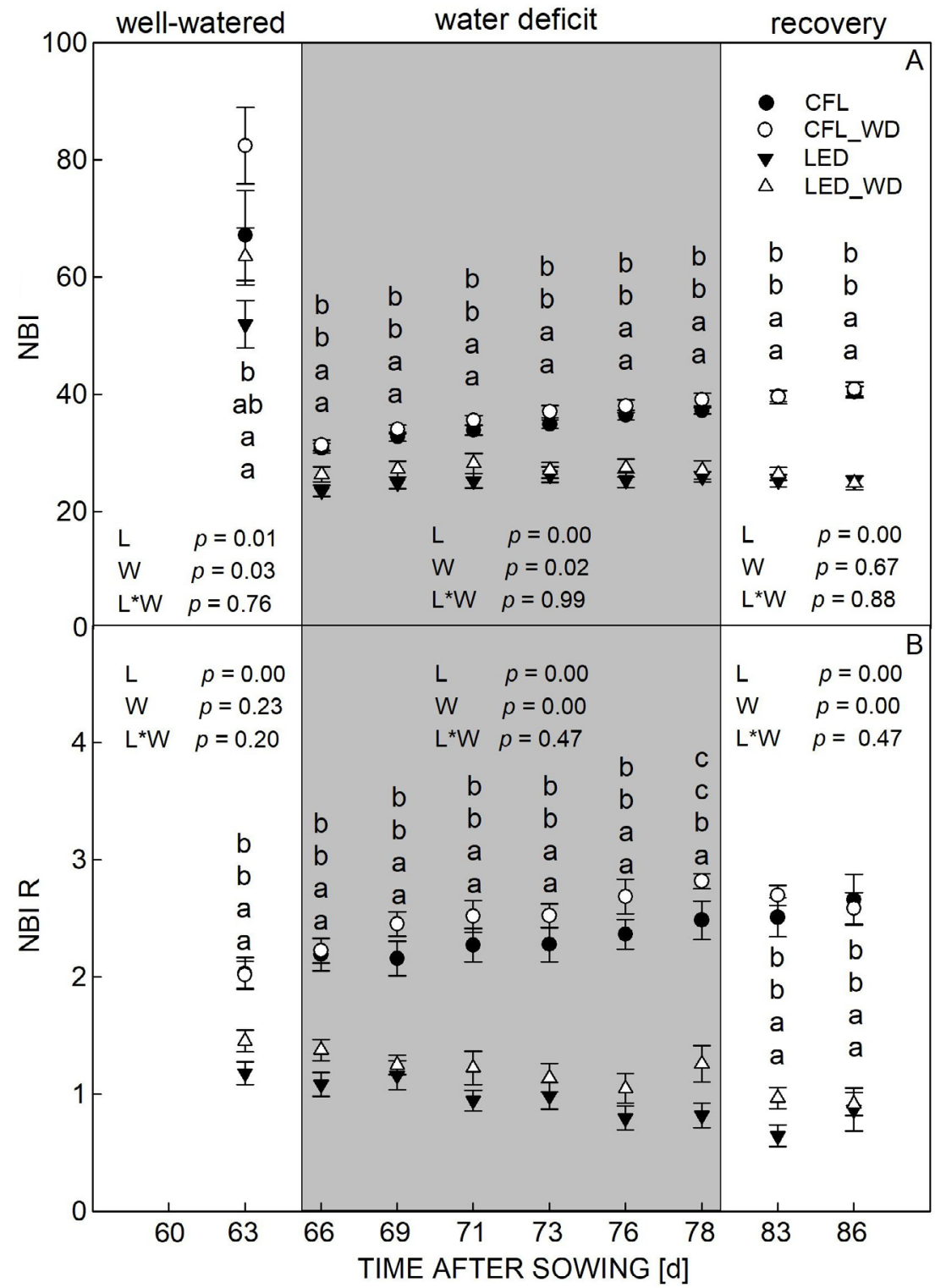

Fig. 3. Nitrogen balance indices NBI $(A)$ and NBI R $(B)$ assessed by Dualex ${ }^{\circledR}$ and Multiplex ${ }^{\circledR}$, respectively, in apple seedlings cultivated in a climate chamber under different radiation sources (CFL - compact fluorescence lamps and LED - light emitting diodes) during well-watered phase $(63 \mathrm{~d})$, progressive water stress $(66-78 \mathrm{~d})$ and recovery ( 83 and $86 \mathrm{~d})$. Treatments: CFL - control plants grown under CFL, CFL_WD - water deficit plants grown under CFL, LED - control plants grown under LED, and LED_WD water deficit plants grown under LED. Means \pm SEs, $n=60$, different letters indicate significant differences between treatments (two-way ANOVA, $\mathrm{L}$ - irradiance, $\mathrm{W}$ - watering, $\mathrm{L} \times \mathrm{W}$ - interaction). 
under LED from 66 DAS onwards. Interestingly, Flav Dx values for both LED treatments increased until the end of the experimental course, whereas values from CFL plants remained stable (Fig. 4A). The Flav Mx index behaved similarly, even though there was a dip in values on 78 DAS for LED_WD plants (Fig. 4B).

Significant differences in $g_{s}$ were seen especially during the water deficit phase (Fig. $5 \mathrm{~A}$ ), with a lower $\mathrm{g}_{\mathrm{s}}$ for water stressed plants grown under LED on 71 DAS. On 76 DAS, both CFL and LED grown plants which were subjected to water deficit further decreased their stomatal conductance. During the recovery period, there were no significant differences between the treatments.

The fluorescence parameter $\mathrm{F}_{\mathrm{v}} / \mathrm{F}_{\mathrm{m}}$ indicates the maximum quantum yield of PS II when all reaction centres are open (Fig. $5 B$ ). The highest $\mathrm{F}_{\mathrm{v}} / \mathrm{F}_{\mathrm{m}}$ ratio was seen in well-watered plants grown under CFL. There were no significant differences between all four treatments during the water deficit phase. However, LED WD plants showed lowest values on 83 DAS (recovery period).

In Fig. 6, there is a comparison of $\mathrm{F}_{\mathrm{v}} / \mathrm{F}_{\mathrm{m}}$ with the performance of Chl fluorescence indices (Chl INDEX and SFR R). On 63 DAS, the treatments cluster around a lower Chl INDEX and low to medium $\mathrm{F}_{\mathrm{v}} / \mathrm{F}_{\mathrm{m}}$ value. Coefficient

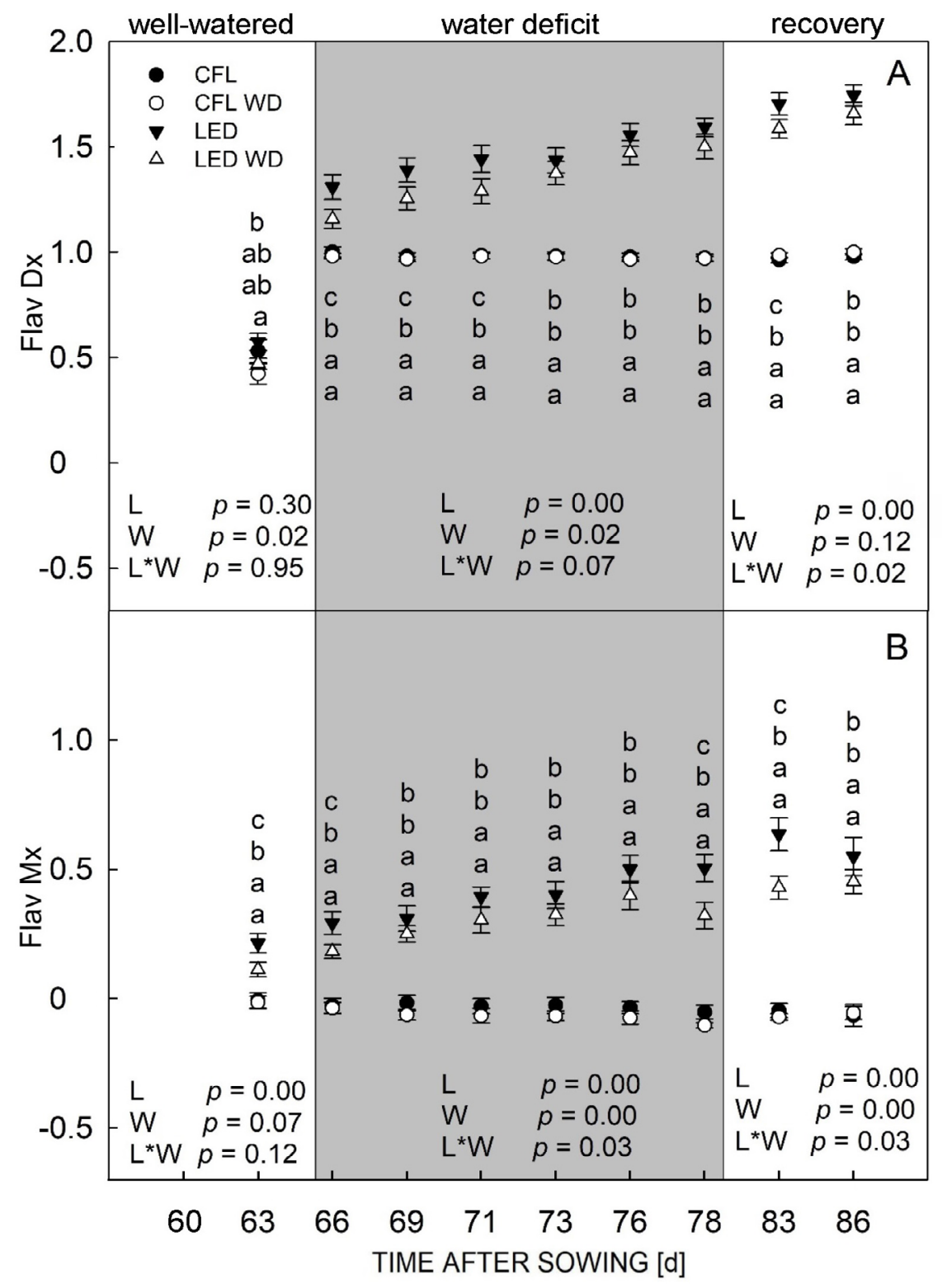

Fig. 4. Flavonol indices Flav Dx $(A)$ and Flav Mx $(B)$ assessed by Dualex ${ }^{\circledR}$ and Multiplex ${ }^{\circledR}$, respectively, in apple seedlings cultivated in a climate chamber under different radiation sources (CFL - compact fluorescence lamps and LED - light emitting diodes) during well-watered phase $(63 \mathrm{~d})$, progressive water stress $(66-78 \mathrm{~d})$ and recovery $(83$ and $86 \mathrm{~d}$ ). Treatments: CFL - control plants grown under CFL, CFL_WD - water deficit plants grown under CFL, LED - control plants grown under LED, and LED_WD water deficit plants grown under LED. Means \pm SEs, $n=60$, different letters indicate significant differences between treatments (two-way ANOVA, $\mathrm{L}$ - irradiance, $\mathrm{W}$ - watering, $\mathrm{L} \times \mathrm{W}$ - interaction). 
of determination shows a high to very high correlation between $\mathrm{Fv} / \mathrm{Fm}$ and Chl INDEX and $\mathrm{F}_{\mathrm{v}} / \mathrm{F}_{\mathrm{m}}$ and SFR R (Fig. 6A,E). In contrast, higher Chl INDEX values are seen for all treatments on 71 DAS (Fig. $6 B$ ) and $F_{v} / F_{m}$ values increase as well on 76 DAS (Fig. 6C), though a lower $R^{2}$ was observed. No clear correlation was seen between $\mathrm{F}_{\mathrm{v}} / \mathrm{F}_{\mathrm{m}}$ and SFR R during the water deficit phase (Fig. $6 F, G$ ). During the recovery period (83 DAS), all treatments show high Chl INDEX and SFR R values. Interestingly, both CFL treatments also have a high $\mathrm{F}_{\mathrm{v}} / \mathrm{F}_{\mathrm{m}}$ ratio (Fig. $6 D, H$ ).

\section{Discussion}

In this study, physiological and biochemical responses of apple seedlings grown under different radiation sources and watering regimes were determined. The hypothesis of this study was that specific radiation conditions might mediate acclimation of apple seedlings to reduce their vulnerability to water deficit.

Radiation quality and watering regimes influenced physiological and biochemical indicators to different extent (Fig. 1). Relative water content is generally viewed as a good index for leaf water status (Bolat et al. 2014). In this study, RWC decreased during water stress (76 DAS) and increased during re-watering (83 DAS), independently

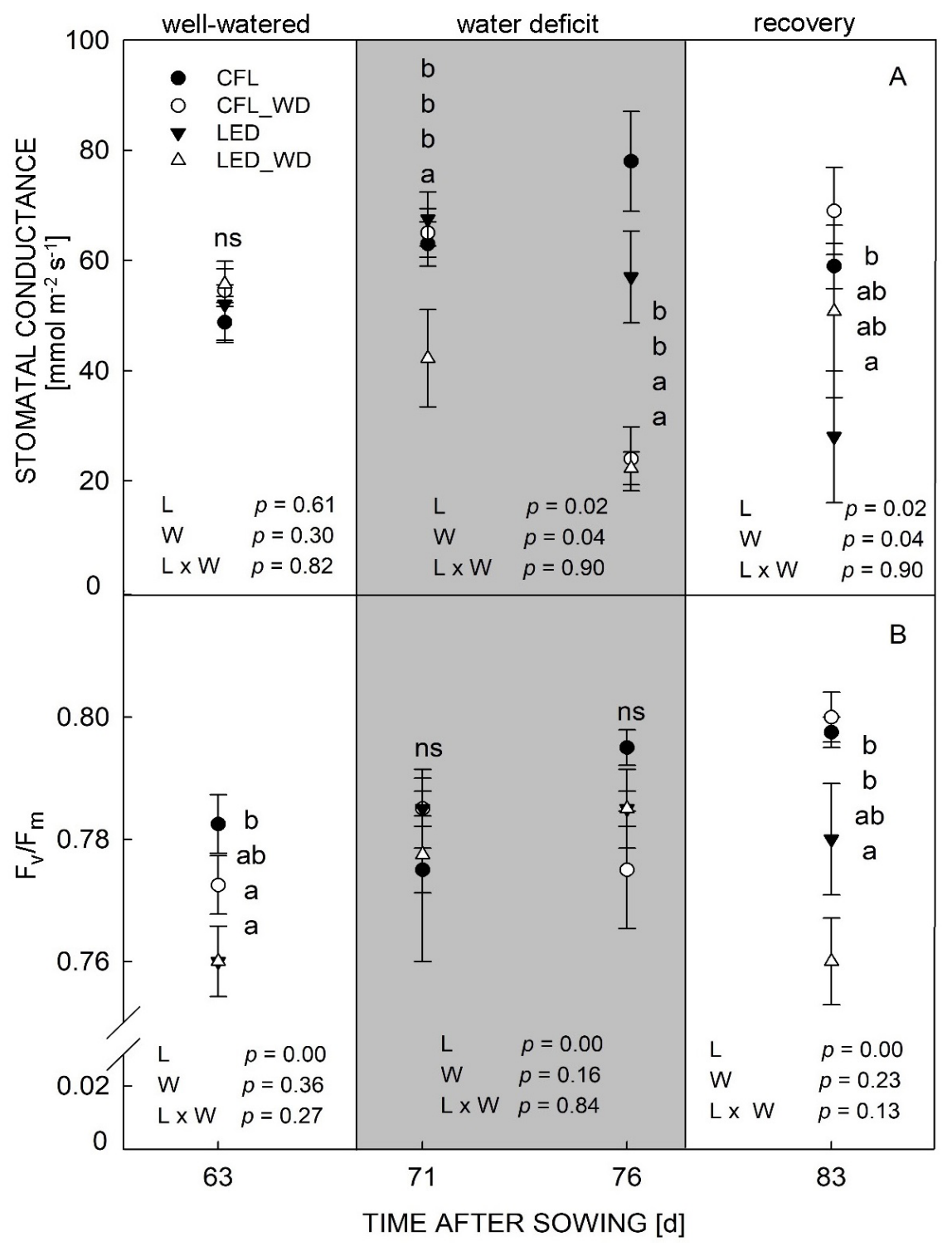

Fig. 5. Stomatal conductance $(A)$ and maximal photochemical efficiency of photosystem $I I\left(\mathrm{~F}_{\mathrm{v}} / \mathrm{F}_{\mathrm{m}}\right)(B)$ of apple seedlings cultivated in a climate chamber under different radiation sources (CFL - compact fluorescence lamps and LED - light emitting diodes) during wellwatered phase $(63 \mathrm{~d})$, progressive water stress $(71$ and $76 \mathrm{~d})$ and recovery $(83 \mathrm{~d})$. Treatments: CFL - control plants grown under CFL, CFL_WD - water deficit plants grown under CFL, LED - control plants grown under LED, and LED_WD - water deficit plants grown under LED. Means \pm SEs, $n=60$, different letters indicate significant differences between treatments (two-way ANOVA, L - irradiance, $\mathrm{W}$ - watering, $\mathrm{L} \times \mathrm{W}$ - interaction). 
of the radiation source. However, the source of ratiation affected $\mathrm{Chl}$ and proline content. Plants cultivated under LED showed lower Chl content and higher proline content during the advanced water deficit period than those grown under CFL. However, this pattern was not followed in the early water deficit and recovery phases, so that further
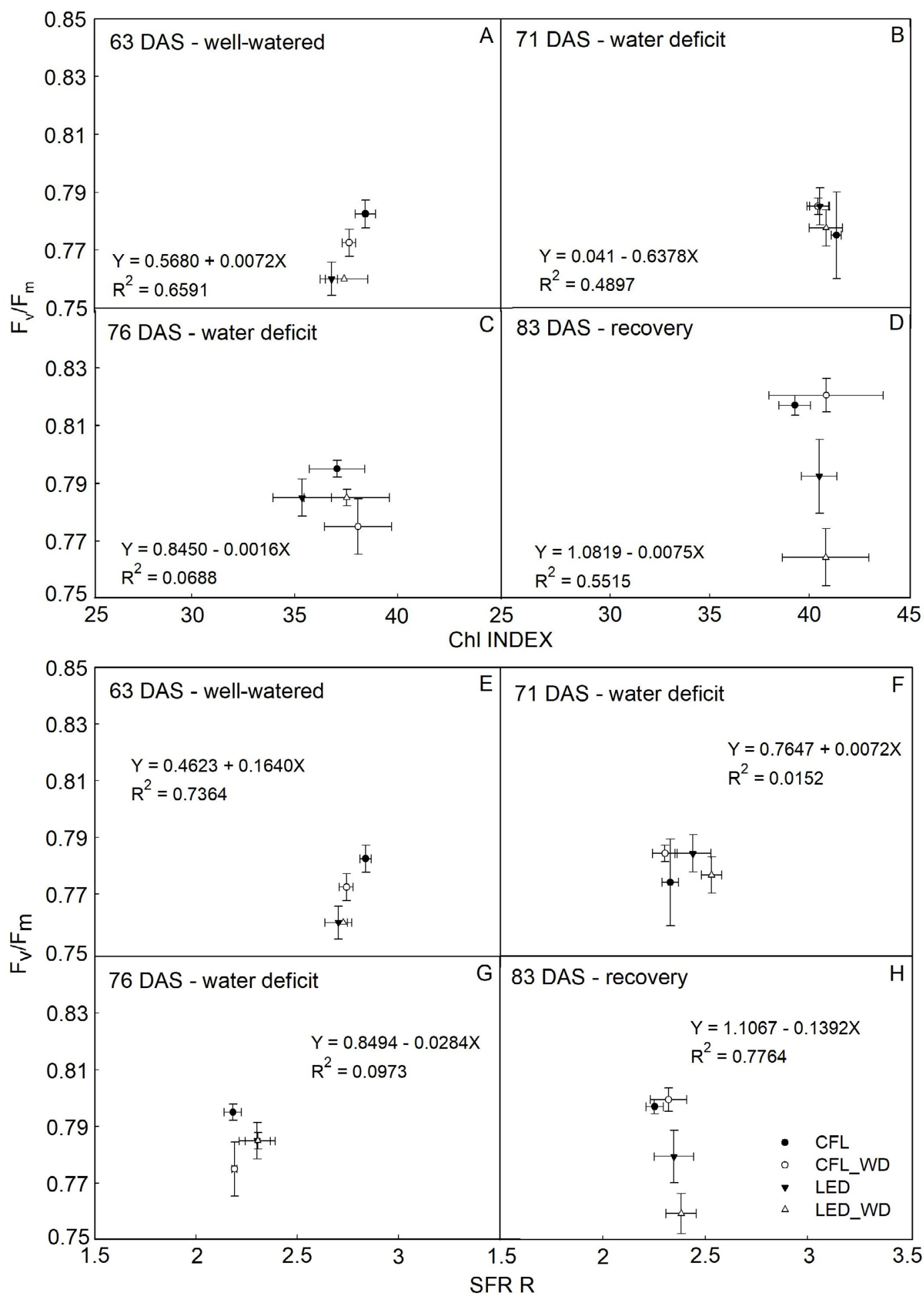

Fig. 6. Comparison between maximal photochemical efficiency $\left(\mathrm{F}_{\mathrm{v}} / \mathrm{F}_{\mathrm{m}}\right)$ and chlorophyll index $(\mathrm{Chl}$ INDEX, $A-D)$ or simple fluorescence ratio with red excitation (SFR R, $E-H$ ) of apple seedlings cultivated in a climate chamber under different radiation sources (CFL compact fluorescence lamps and LED - light emitting diodes) during well-watered phase (63 DAS), progressive water stress (71 and 76 DAS) and recovery (83 DAS). Treatments: CFL - control plants grown under CFL, CFL WD - water deficit plants grown under CFL, LED - control plants grown under LED, and LED_WD - water deficit plants grown under LED. Means \pm SEs, $n=16$ (two-way ANOVA). 
studies with longer water deficit periods are necessary. Wang et al. (2015), working with Houttuynia cordata seedlings, observed high RWC and Chl content in plants grown under fCFL and red LED. In general, proline accumulates in plants at a low water potential caused by drought, describing it as a suitable biochemical indicator of water stress in plants (Hayat et al. 2012). However, blue- and red-radiation sources were also found to regulate proline accumulation, especially when combined with low water potential under drought and salinity (Kovács et al. 2019).

The $\mathrm{F}_{\mathrm{v}} / \mathrm{F}_{\mathrm{m}}$ reflects the maximal photochemical efficiency of the active centre of PS II in the dark (Krause and Weis 1991, Kalaji and Guo 2008). In this study, slightly higher photosynthetic efficiency was seen in CFL plants during the well-watered conditions and recovery phases (Fig. 5B). Wang et al. (2015) verified higher $\mathrm{F}_{\mathrm{v}} / \mathrm{F}_{\mathrm{m}}$ for plants grown under CFL and blue radiation modules, supporting higher radiation absorption in treatments with blue than with red LED. This might explain the lower performance of plants under LED in the present study, since blue radiation, according to the proportion R:B $(2: 1)$, was provided to a lesser extent. Wang et al. (2015) assume that the different absorption might influence $\mathrm{CO}_{2}$ assimilation rates of plants grown under radiation with distinct wavelengths.

Additionally, radiation quality and watering regime also impacted $\mathrm{g}_{\mathrm{s}}$ (Fig. 5A). It is known that drought stress impairs stomatal conductance and ultimately results in stomatal closure to avoid water loss and simultaneously limit gas exchange (Jaleel et al. 2009). Blue radiation has been found to be more effective than red radiation in causing stomatal opening or preventing stomatal closure (Farquhar and Sharkey 1982, Shimazaki et al. 2007). This could explain the lower stomatal conductance in plants grown under LED during the early water deficit phase, though it apparently did not directly affect maximal photochemical efficiency.

Indices obtained by portable fluorescence sensors related to Chl estimation (Chl INDEX and SFR R) expressed increasing values throughout the experimental period (Fig. 2). The increase of Chl INDEX and SFR $\mathrm{R}$ in plants grown under LED occurred due to blue and red radiation absorption by the $\mathrm{Chl}$ molecules promoting more dark green leaves and accumulation of secondary metabolites (Runkle 2015). However, no correlation of Chl fluorescence indices was given with $\mathrm{Chl}$ content. Compared with $\mathrm{F}_{\mathrm{v}} / \mathrm{F}_{\mathrm{m}}$, both Chl INDEX and SFR R revealed an opposite disposition (Fig. 6) since the Imaging-PAM parameter reproduced the tendency of the wet-chemically assessed Chl content

However, clear differences were verified regarding the nitrogen balance indices NBI and NBI R (Fig. 3). Both nitrogen indices showed higher mean values for plants grown under CFL lamps, similarly to the pattern of leaf Chl content. Nitrogen is part of the $\mathrm{Chl}$ molecule (Tremblay et al. 2012) and therefore has a direct relation with the amount of $\mathrm{Chl}$ accumulated in the mesophyll. Cerovic et al. (2012) described a direct relation between nitrogen and $\mathrm{Chl}$ by analysing the efficiency of Chl fluorescence to estimate the nitrogen status in crops by using the same leaf clip used in the present work. Moreover, Abdallah et al. (2016) reported the practical usage of fluorescence indices, indicating the ratio $\mathrm{Chl}$ content and phenolic compounds (Chl/Flav) as an initial basis to estimate leaf nitrogen balance.

Increased mean values of Flav Dx and Flav Mx were recorded in plants grown under LED radiation source from 66 DAS onwards (Fig. 4). These indices are related to the accumulation of phenolic compounds in leaf epidermis, including flavonoids and flavonols. The latter increased with higher sun light in Gingko biloba seedling leaves (Xu et al. 2014). This could be UV or, as in the present study, LED radiation, which has more red and blue radiation in its spectrum than CFL lamps. Bantis et al. (2016) showed a significant increase in total phenolic content in Ocimum basilicum cultivated under the combination of high blue and green, high red:far-red (R/FR), and $1 \%$ UV. It is known that the accumulation of flavonols and further secondary metabolites in plant cells is triggered in order to overcome stressful conditions. In addition, their synthesis can change due to environmental, physiological, and genetic factors (Zhao et al. 2005), with irradiance being one of the most influential factors (Kopsell et al. 2004, Kopsell and Sams 2013).

\section{Conclusions}

Here, we show that LED with their specific spectral regions were not able to efficiently shield plants from water stress. In contrast, plants grown under a wider spectral range (CFL) performed better during and after a short period of water withdrawal, corroborated by fluorescence indices related to the nitrogen balance (NBI and NBI R) and the $\mathrm{Chl}$ content. Phenolic compounds accumulation in leaf epidermis could also be well reproduced by flavonol indices (Flav Dx and Flav Mx), showing their higher content both in well-watered and water restricted plants set under LED. Hence, fluorescence indices related to nitrogen balance and flavonol accumulation promise to be a useful non-destructive tool to estimate physiological status of apple seedlings under different radiation sources and watering regimes. However, further studies should focus on different PPFD and spectra of LED lamps, and whether set up changes during the early cultivation phase of tree species would maximise a possible protective LED effect against water restrictions in older plants.

\section{References}

Abrahám, E., Hourton-Cabassa, C., Erdei, L., Szabados, L.: Methods for determination of proline in plants. - In: Sunkar, R. (ed.): Plant Stress Tolerance. Methods in Molecular Biology (Methods and Protocols). Vol. 639: Pp. 317-331. Humana Press, Totowa 2010.

Astolfi, S., Marianello, C., Grego, S., Bellarosa, R.: Preliminary investigation of LED lighting as growth light for seedlings from different tree species in growth chambers. - Not. Bot. Hort. Agrobot. Cluj 40: 31-38, 2012. 
Bantis, F., Ouzounis, T., Radoglou, K.: Artificial LED lighting enhances growth characteristics and total phenolic content of Ocimum basilicum, but variably affects transplant success. Scientia Hort. 198: 277-283, 2016.

Barrs, H.D., Weatherley, P.E.: A re-examination of the relative turgidity technique for estimating water deficits in leaves. Aust. J. biol. Sci. 15: 413-428, 1962.

Abdallah, F.B, Philippe, W., Goffart, J.P.: [Use of chlorophyll fluorescence for the evaluation of crop nitrogen status. A review.] - Biotechnol. Agron. Soc. Environ. 20: 83-93, 2016. [In French]

Bolat, I., Dikilitas, M., Ercisli, S., Ikinci, A., Tonkaz, T.: The effect of water stress on some morphological, physiological, and biochemical characteristics and bud success on apple and quince rootstocks. - Sci. World J. 2014: 769732, 2014.

Bürling, K., Cerovic, Z.G., Cornic, G., Ducruet, J.M., Noga, G., Hunsche, M.: Fluorescence-based sensing of drought-induced stress in the vegetative phase of four contrasting wheat genotypes. - Environ. exp. Bot. 89: 51-59, 2013.

Bürling, K., Hunsche, M., Noga. G.: Use of blue-green and chlorophyll fluorescence measurements for differentiation between nitrogen deficiency and pathogen infection in winter wheat. - J. Plant Physiol. 168: 1641-1648, 2011.

Buschmann, C., Lichtenthaler, H.K.: Contribution of chlorophyll fluorescence to the reflectance of leaves in stressed plants as determined with the VIRAF-spectrometer. - Z. Naturforsch. C. 54: 849-855, 1999.

Cerovic, Z.G., Masdoumier, G., Ghozlen, N.B., Latouche, G.: A new optical leaf-clip meter for simultaneous non-destructive assessment of leaf chlorophyll and epidermal flavonoids. Physiol. Plant. 146: 251-260, 2012.

Chen, C., Xiao, Y., Li, X., Ni, M.: Light-regulated stomatal aperture in Arabidopsis. - Mol. Plants 5: 566-572, 2012.

Ghozlen, N.B, Cerovic, Z.G., Germain, C., Toutain, S., Latouche, G.: Non-destructive optical monitoring of grape maturation by proximal sensing. - Sensors (Basel) 10: 10040-10068, 2010.

González, L., González-Vilar, M.: Determination of relative water content. - In: Manuel, J., Reigosa, R. (ed.): Handbook of Plant Ecophysiology Techniques. Pp. 207-212. Springer, Dorderecht 2001.

Farquhar, G.D., Sharkey, T.D.: Stomatal conductance and photosynthesis. - Annu. Rev. Plant Physiol. 33: 317-345, 1982.

Gitelson, A., Buschmann, C., Lichtenthaler, H.: The chlorophyll fluorescence ratio $\mathrm{F}_{735} / \mathrm{F}_{700}$ as an accurate measure of the chlorophyll content in plants. - Remote Sens. Environ. 69: 296-302, 1999.

Hamann, F.A., Czaja, S., Hunsche, M., Noga, G., Fiebig, A.: Monitoring physiological and biochemical responses of two apple cultivars to water supply regimes with non destructive fluorescence sensors. - Scientia Hort. 242: 51-61, 2018.

Hayat, S., Hayat, Q., Alyemeni, M.S., Wani, A.S., Pichtel, J., Ahmad, A.: Role of proline under changing environments. Plant Signal. Behav. 7: 1456-1466, 2012.

Hoffmann, A., Noga, G., Hunsche, M.: Acclimations to light quality on plant and leaf level affect the vulnerability of pepper (Capsicum annuum L.) to water deficit. - J. Plant Res. 2: 295-306, 2015.

Jaleel, C.A., Manivannan, P., Wahid, A., Farooq, M., Al-Juburi, H.J., Somasundaram R., Panneerselvam, R.: Drought stress in plants: a review on morphological characteristics and pigments composition. - Int. J. Agr. Biol. 11: 100-105, 2009.

Kalaji, M.H., Guo, P: Chlorophyll fluorescence: a useful tool in barley plant breeding programs. - In: Sánchez, A., Gutierrez, J.S. (ed.): Photochemistry Research Progress. Pp 439-463. Nova Science Publishers, New York 2008.
Kautz, B., Noga, G., Hunsche, M.: Sensing drought- and salinityimposed stresses on tomato leaves by means of fluorescence techniques. - Plant Growth Regul. 73: 279-288, 2014.

Kautz, B., Noga, G., Hunsche, M.: PEG and drought cause dinstict changes in biochemical, physiological and morphological parameters of apple seedlings. - Acta Physiol. Plant. 37: 162, 2015.

Kim, H.H., Wheeler, R., Sager, J.C., Yorio, N.C., Goins, G.D.: Light-emitting diodes as an illumination source for plants: a review of research at Kennedy Space Center. - Habitation 10: 71-78; 2005.

Kopsell, D.A., Kopsell, D.E., Lefsrud, M.G., CurranCelentano, J., Dukach, L.E.: Variation in lutein, $\beta$-carotene, and chlorophyll concentrations among Brassica oleracea cultigens and seasons. - HortScience 39: 361-364, 2004.

Kopsell, D.A., Sams, C.E.: Increases in shoot tissue pigments, glucosinolates and mineral elements in sprouting broccoli after exposure to short-duration blue light from light emitting diodes. - J. amer. Soc. hort. Sci. 138: 31-37, 2013.

Kovács, H., Aleksza, D., Baba, A.I., Hajdu, A., Király, A.M., Zsigmond, L., Tóth, S.Z., Kozma-Bognár, L., Szabados, L.: Light control of salt-induced proline accumulation is mediated by elongated hypocotyl 5 in Arabidopsis. - Front. Plant Sci. 10: 1584, 2019.

Krause, G.H., Weis, E.: Chlorophyll fluorescence and photosynthesis: the basics. - Annu. Rev. Plant Physiol. Plant mol. Biol. 42: 313-349, 1991.

Leufen, G., Noga, G., Hunsche, M.: Fluorescence indices for the proximal sensing of powdery mildew, nitrogen supply and water deficit in sugar beet leaves. - Agriculture 4: 58-78, 2014.

Lichtenthaler, H.K., Babani, F., Navrátil, M., Buschmann, C.: Chlorophyll fluorescence kinetics, photosynthetic activity, and pigment composition of blue-shade and half-shade leaves as compared to sun and shade leaves of different trees. Photosynth. Res. 117: 355-366, 2013.

Loreto, F., Tsonev, T., Centritto, M.: The impact of blue light on leaf mesophyll conductance. - J. exp. Bot. 60: 2283-2290, 2009.

Massa, G.D., Kim, H.H., Wheeler, R.M., Mitchell, C.A.: Plant productivity in response to LED lighting. - HortScience 43: 1951-1956, 2008.

Maxwell, K., Johnson, G.N.: Chlorophyll fluorescence - a practical guide. - J. exp. Bot. 51: 659-668, 2000.

Mullan, D., Pietragalla, J.: Leaf relative water content. - In: Pask, A., Pietragalla, J., Reynolds, M. (ed.): Physiological Breeding II: A Field Guide to Wheat Phenotyping. Pp. 25-27. International Maize and Wheat Improvement Center, Mexico City 2012.

Nouri, M.Z., Moumeni, A., Komatsu, S.: Abiotic stresses: insight into gene regulation and protein expression in photosynthetic pathways of plants. - Int. J. mol. Sci. 16: 20392-20416, 2015.

Osakabe, Y., Osakabe, K., Shinozaki, K., Tran, L.S.P.: Response of plants to water stress. - Front. Plant Sci. 5: 1-8, 2014.

Roháček, K., Soukupová, J., Barták, M.: Chlorophyll fluorescence: a wonderful tool to study plant physiology and plant stress. - In: Schoefs, B. (ed.): Plant Cell Compartments Selected Topics. Pp. 41-104. Research Signpost, Kerala 2008.

Runkle, E.: Light Wavebands and Their Effects on Plants Michigan State University, East Lansing 2015.

Shimazaki, K., Doi, M., Assmann, S.M., Kinoshita, T.: Light regulation of stomatal movement. - Annu Rev Plant Biol. 58: 219-247, 2007.

Strobl, A., Türk, R.: Investigations on the chlorophyll content of some subalpine lichens. - Phyton 30: 247-264, 1990.

Terashima, I., Fujita, T., Inoue, T., Chow, W.S., Oguchi, R.: Green light drives leaf photosynthesis more efficiently than red light 
in strong white light: revisiting the enigmatic question of why leaves are green. - Plant Cell Physiol. 50: 684-697 2009.

Tremblay, N., Wang, Z., Cerovic, Z.G: Sensing crop nitrogen status with fluorescence indicators. a review. - Agron. Sustain. Dev. 32: 451-464, 2012.

Wang, Z., Tian, J., Yu, B., Yang, L., Sun, Y.: LED light spectrum affects the photosynthetic performance of Houttuynia cordata seedlings. - Amer. J. Optics Photonics 3: 38-42, 2015.

Xu, Y., Wang, G., Cao, F., Zhu, C., Wang, G., El-Kassaby, Y. A.: Light intensity affects the growth and flavonol biosynthesis of ginkgo (Ginkgo biloba L.). - New Forest. 45: 765-776, 2014.
Zeiger, E., Field, C.: Photocontrol of the functional coupling between photosynthesis and stomatal conductance in the intact leaf. - Plant Physiol. 70: 370-375, 1982.

Zhang, Y., Tremblay, N., Zhu, J.: A first comparison of Multiplex ${ }^{\circledR}$ for the assessment of corn nitrogen status. - J. Food Agr. Environ. 10: 1008-1016, 2012.

Zhao, D., Reddy, K.R., Kakani, V.G., Reddy, V.R.: Nitrogen deficiency effects on plant growth, leaf photosynthesis, and hyperspectral reflectance properties of sorghum. - Eur. J. Agron. 22: 391-403, 2005. 